\title{
Relationship of Increased Plasma Atrial Natriuretic Factor and Renal Sodium Handling During Immersion-induced Central Hypervolemia in Normal Humans
}

\author{
Murray Epstein, Rodger Loutzenhiser, Edward Friedland, Rose M. Aceto," Maria J. F. Camargo, and Steven A. Atlas* \\ Nephrology Section, Veterans Administration Medical Center and the University of Miami School of Medicine, Miami, Florida 33125, \\ and the *Cardiovascular Center, New York Hospital, Cornell Medical Center, New York 10021
}

\begin{abstract}
Although maneuvers augmenting atrial volume and/or stretch also augment plasma levels of atrial natriuretic factor (ANF), the role of ANF in modulating renal sodium and water handling has not been defined. Water immersion to the neck (NI) was employed to assess the ANF response to acute volume expansion in 13 seated sodium-replete normal subjects. ANF increased promptly and markedly from $7.8 \pm 1.8$ to $19.4 \pm 3.8 \mathrm{fmol} / \mathrm{ml}$, then declined to $6.3 \pm 1.4 \mathrm{fmol} / \mathrm{ml}$ after $60 \mathrm{~min}$ recovery. Concomitantly, NI increased urine flow rate $(V)(2.0 \pm 0.6$ to $7.0 \pm 0.9 \mathrm{ml} /$ min; $P<0.001)$ and sodium excretion $\left(U_{\mathrm{Na}} V\right)(92 \pm 12$ to $191 \pm 15$ $\mu \mathrm{eq} / \mathrm{min} ; P<0.001)$, and decreased PRA $(-66 \pm 3 \%)$ and plasma aldosterone $(-57 \pm 6 \%)$. Increases of plasma ANF ranged from $<20 \%$ to over 12-fold. Similarly, the natriuretic response to NI varied markedly from none to $500 \%$. There was a strong correlation between peak $A N F$ and peak $U_{\mathrm{Na}} V(r=0.67 ; P<0.025)$, but none between peak $V$ and peak plasma ANF $(r=-0.10 ; P$ $>0.5$ ). These findings suggest that an increase in plasma ANF contributes to the natriuretic response to NI, implying a physiological role for ANF in modulating volume homeostasis in humans.
\end{abstract}

\section{Introduction}

Although the potent natriuretic and renal hemodynamic effects of atrial natriuretic factor (ANF) ${ }^{1}$ have been clearly documented $(1-4)$, its role in modulating volume and circulatory homeostasis has not been established. ANF is contained in secretory granules of the atria (3) and immunoreactive ANF (irANF) has been detected in animal and human plasma (5-10). Recent evidence suggests that maneuvers that augment atrial volume and/or stretch lead to increases in plasma irANF $(6,10,11)$. Because similar events can clearly alter renal excretory function (12), it seems possible that augmentation of ANF release may contribute to the renal effects of cardiopulmonary blood volume expansion.

Previous studies have demonstrated that head-out water immersion produces a prompt, marked, and sustained central hy-

Address correspondence to Murray Epstein, M.D., Nephrology Section (111C1), Veterans Administration Medical Center, 1201 N.W. 16th St., Miami, FL 33125.

Received for publication 16 June 1986 and in revised form 20 November 1986.

1. Abbreviations used in this paper: ANF, atrial natriuretic factor; $\mathrm{C}_{\mathrm{Cr}}$, creatinine clearance; $\mathrm{C}_{\mathrm{H}_{2} \mathrm{O}}$, free water clearance; irANF, immunoreactive ANF; NI, neck immersion; PA, plasma aldosterone; PRA, plasma renin activity; TFA, trifluoroacetic acid; $U_{\mathbf{K}} \mathrm{V}$, rate of potassium excretion; $U_{\mathrm{Na}} \mathrm{V}$, sodium excretion; $U_{o s m}$, urinary solute concentration; $V$, urinary flow rate.

The Journal of Clinical Investigation, Inc.

Volume 79, March 1987, 738-745 pervolemia without the necessity of infusing exogenous volume expanders and thus altering plasma composition (12-15). In a preliminary report from our laboratories, we demonstrated in four normal subjects that head-out water immersion is associated with stimulation of ANF (10). This pilot study provided preliminary characterization of the ANF response to central hypervolemia. Nevertheless, the relationship of ANF to immersioninduced alterations in renal sodium and water handling and in plasma levels of renin, aldosterone, and cortisol remains undefined. The present study was undertaken to examine these relationships more critically. This seemed particularly appropriate in view of our repeated demonstration of the marked heterogeneity of renal excretory responses to immersion among normal subjects (12-15). Although the reasons for this variable response are poorly understood, we hoped to take advantage of this phenomenon in an attempt to better define the functional significance of increases in plasma ANF during central hypervolemia.

\section{Methods}

A total of 19 studies (6 control and 13 during water immersion to the neck NI) were carried out in 18 male subjects between the ages of 20 and 39 yr. All had a negative history for hypertension, cardiovascular disease, and diabetes. Clinically apparent renal disease was excluded in all subjects by documenting the presence of a normal urine sediment and creatinine clearance and the absence of proteinuria. The use of alcohol, tobacco, tea, coffee, and all medications was prohibited for at least $24 \mathrm{~h}$ before and during each of the studies. The experimental protocols were similar and were carried out as follows.

Following $10 \mathrm{~h}$ of overnight fluid restriction, the subject was instructed to sit quietly. At 08:00 h, after voiding and completely emptying his bladder, the subject once again assumed the seated position. Immediately after the subjects had voided, a 18-gauge, 1.5-in Teflon catheter with a flash chamber and an accompanying Teflon stylet (Jelco, Raritan, NJ) was inserted into a forearm vein, permitting sequential sampling of blood without the use of an anticoagulant or an i.v. infusion. Venous blood was drawn using a prechilled 10-ml polystyrene disposable syringe. After each sample was obtained, a sterile stylet was inserted into the catheter. After a 60 -min prestudy period, the subject sat quietly in the study tank immersed in water to the neck for $3 \mathrm{~h} \mathrm{(09:00-12:00} \mathrm{h);} \mathrm{this} \mathrm{was} \mathrm{followed}$ by a $1-\mathrm{h}$ recovery period of quiet sitting outside the tank. For control, the subject sat quietly outside the immersion tank for the 5-h period. Blood samples were obtained before and after the study for sodium, potassium, osmolality, and creatinine determinations. Samples for plasma renin activity (PRA), plasma aldosterone (PA), plasma cortisol, and irANF were obtained every $30 \mathrm{~min}$ during the prestudy period, at $15,30,60$, 120 , and $180 \mathrm{~min}$ of immersion, and at 15,30 , and $60 \mathrm{~min}$ during the recovery period. Each subject was requested to void spontaneously at hourly intervals during the studies. To void during the immersion period, the subjects stood briefly on a platform in the immersion tank after collection of blood. To maintain adequate urine flow, an initial waterload of $400 \mathrm{ml}$ was administered, and subsequently $200 \mathrm{ml}$ of water was ingested hourly. Sodium, potassium, osmolality and creatinine were measured in all urine samples. Immersion was carried out in a waterproof tank described in detail previously (12-15). A constant water temperature 
of $34.5 \pm 0.5^{\circ} \mathrm{C}$ was maintained by two heat exchangers, as detailed previously (12-15).

Blood for PRA, PA, plasma cortisol, and plasma irANF measurements was placed immediately into chilled vacutainer tubes containing potassium EDTA, and the plasma was separated with a refrigerated centrifuge. The samples were flash frozen with dry ice and acetone and then stored at $-76^{\circ} \mathrm{C}$.

PRA, PA, and plasma cortisol were assayed by radioimmunoassay as reported previously $(16,17)$. Plasma ANF was measured by radioimmunoassay following extraction on $\mathrm{C}_{18}$ Sep-Pak cartridges (Waters Instruments, Inc., Rochester, MN). Plasma samples $(3 \mathrm{ml})$ were applied to individual prewashed cartridges, which were then washed with $\mathrm{H}_{2} \mathrm{O}$ $(3 \mathrm{ml}), 0.1 \%$ trifluoroacetic acid (TFA, $3 \mathrm{ml}$ ) and $20 \%$ acetonitrile in $0.1 \%$ TFA $(3 \mathrm{ml})$. irANF was then eluted with $80 \%$ acetonitrile in $0.1 \%$ TFA ( 2 washes, $3 \mathrm{ml}$ each), and the pooled extract was dried overnight in a Savant Speed-Vac evaporator. Recoveries of ANF standard and radiolabeled ANF were $74 \pm 9 \%$ (SE) and $78 \pm 7 \%$, respectively (range, $58-84 \%)$. Recoveries in individual samples were determined by addition of ${ }^{125}$ I-ANF $(1,000 \mathrm{cpm})$ to the plasma before extraction. Two radioimmunoassay systems were employed. Initial studies (e.g., subject 1 ) were performed with a heterologous assay using an antiserum (1:15,000 final dilution) raised in rabbits immunized with the synthetic 24-residue rat auriculin A (18) coupled to bovine thyroglobulin; the 25-residue rat auriculin $\mathrm{B}$, used as tracer, was prepared by reaction with $\mathrm{Na}^{125} \mathrm{I}$ in the presence of solid-phase chloramine T (Iodo-Beads, Pierce Chemical Co., Rockford, IL) and purification on $\mathrm{C}_{18}$ Sep-Pak cartridges and reversephase high-performance liquid chromatography (specific activity, $\sim 2,000 \mathrm{Ci} / \mathrm{mmol}$ ). The antiserum showed $94 \%$ crossreactivity with the 28-residue rat ANP (cardionatrin I) and $61 \%$ crossreactivity with its human analogue, hANP (Peninsula Laboratories Inc., Belmont, CA). Subsequent studies employed antiserum, prepared against $\alpha$-hANP (Peninsula Laboratories Inc.) at a final dilution of 1:21,000, and ${ }^{125}$ I-hANP as tracer. The standard used in both assays for the values reported herein was $\alpha$ hANP, and there was excellent agreement between the two assays. Extracts were reconstituted in $250 \mu \mathrm{l}$ of assay buffer $(0.1 \mathrm{M}$ sodium phosphate, $\mathrm{pH} 7.5$, containing $0.3 \%$ bovine serum albumin and $0.3 \%$ bovine gamma globulin) and duplicate $100-\mu \mathrm{l}$ aliquots of unknowns or standard were incubated with diluted antiserum $(100 \mu \mathrm{l})$ for $24 \mathrm{~h}$ at $4^{\circ} \mathrm{C}$. Tracer $(10,000$ cpm in $100 \mu$ l assay buffer) was then added and the reaction continued for $18 \mathrm{~h}$ at $4^{\circ} \mathrm{C}$. Bound and free peptide were separated by addition of $15 \%$ polyethylene glycol $(2 \mathrm{ml})$, and results were calculated from standard curves of bound/free counts per minute vs. log ANF standard. The sensitivities of the heterologous and homologous assays were $5.5 \mathrm{fmol}$ ( $\mathrm{IC}_{50}$, $89 \pm 5 \mathrm{fmol})$ and $0.7 \mathrm{fmol}\left(\mathrm{IC}_{50}, 5.4 \pm 0.3 \mathrm{fmol}\right)$, respectively.

Analytic methods for sodium, potassium, and creatinine have been reported previously (13-15).

In the presentation of the data, mean values are followed by the standard error of the mean as an index of dispersion. Data were evaluated statistically by analysis of variance and by paired or unpaired $t$ tests. Differences with $P<0.05$ were considered significant.

Permission for the study was obtained from each subject after a detailed description of the procedure and potential complications. The protocol was approved by the Human Experimentation Committees of the University of Miami School of Medicine and the Miami Veterans Administration Medical Center and was in compliance with the principles set forth in the Declaration of Helsinki. No complications occurred.

\section{Results}

Plasma ANF levels. The effects of a time control study and water immersion on plasma ANF levels are summarized in Table I and Fig. 1. As depicted in Table I, plasma ANF sequentially determined in six seated control subjects over a 5-h interval was markedly constant. Mean values ranged from $5.6 \pm 0.3$ to $7.4 \pm 1.0$ $\mathrm{fmol} / \mathrm{ml}$. In contrast, immersion induced a marked augmentation of plasma ANF. As depicted in Fig. 1, replicate ANF levels were remarkably constant when sampled at 30 -min intervals during the preimmersion hour, the mean values ranging between $6.5 \pm 1.3$ and $7.8 \pm 1.8 \mathrm{fmol} / \mathrm{ml}$. In response to immersion, ANF increased promptly and markedly. By $30 \mathrm{~min}$ of immersion, mean plasma ANF levels had doubled to $15.0 \pm 3.6 \mathrm{fmol} / \mathrm{ml}(P$ $<0.05)$, with a maximum mean response $(19.4 \pm 3.8 \mathrm{fmol} / \mathrm{ml})$ attained by the end of the second hour. The magnitude of the increase in ANF levels varied markedly among the individuals, ranging from as low as $20 \%$ above baseline to as much as 12 fold above baseline. The increase in absolute levels of ANF ranged from $<1$ to $39 \mathrm{fmol} / \mathrm{ml}$ above baseline, with four subjects manifesting increases of $>20 \mathrm{fmol} / \mathrm{ml}$, six subjects manifesting increases of 8-14 $\mathrm{fmol} / \mathrm{ml}$, and the remaining three subjects manifesting increases of $<2 \mathrm{fmol} / \mathrm{ml}$. Among the 10 subjects with ANF increases of $>2 \mathrm{fmol} / \mathrm{ml}$, peak responses were attained by $60 \mathrm{~min}$ in two subjects, $120 \mathrm{~min}$ in six subjects, and not until $180 \mathrm{~min}$ of immersion in two subjects.

The augmentation of ANF was sustained throughout immersion, the levels remaining $>50 \%$ above baseline at $180 \mathrm{~min}$ in 11 of the 13 subjects. Cessation of immersion was associated with a prompt offset. By $30 \mathrm{~min}$ of recovery, plasma irANF had decreased by $>50 \%$ in 8 of the 13 subjects. By 60 min of recovery, plasma irANF had returned to preimmersion values in 12 of 13 subjects.

An examination of the relationship between basal levels of sodium excretion and the subsequent rise in ANF disclosed that ANF stimulation varied independently of basal $\mathrm{U}_{\mathrm{Na}} \mathrm{V}(\mathrm{r}=0.22$; $P>0.4)$.

$P R A$. The effects of a time control study and water immersion on PRA are summarized in Table I and Fig. 2. As depicted in Table I, PRA remained constant in seated control subjects, ranging from $3.1 \pm 0.7$ to $4.0 \pm 1.2 \mathrm{ng} / \mathrm{ml} / \mathrm{h}$ over the 5 -h interval. In contrast, immersion induced a marked suppression of PRA. As depicted in Fig. 2, the three sequential PRA levels obtained at 30 -min intervals during the prestudy hour were stable, the mean values ranging between $4.0 \pm 1.0$ and $4.4 \pm 1.0 \mathrm{ng} / \mathrm{ml} / \mathrm{h}$. Immersion resulted in a significant suppression of PRA beginning within 15 min of study $(P<0.001$ compared with prestudy values). By $180 \mathrm{~min}, \mathrm{PRA}$ was suppressed to $33 \pm 3 \%$ of the prestudy value $(P<0.005)$. Cessation of immersion was associated with a prompt return toward prestudy values as early as $15 \mathrm{~min}$

Table I. Temporal Variations in Plasma irANF and PRA Values Obtained from Six Normal Subjects During a 5-h Seated Control Study

\begin{tabular}{lllllllll}
\hline & Minutes & & & & & \\
\cline { 2 - 7 } & 0 & 30 & 60 & 90 & 120 & 180 & 240 & 300 \\
\hline irANF $(\mathrm{fmol} / \mathrm{ml})$ & $6.8 \pm 0.8$ & $6.2 \pm 0.9$ & $7.4 \pm 1.0$ & $6.6 \pm 0.6$ & $6.7 \pm 0.4$ & $5.6 \pm 0.3$ & $6.1 \pm 0.5$ & $5.7 \pm 0.3$ \\
PRA $(\mathrm{ng} / \mathrm{ml} / \mathrm{h})$ & $3.1 \pm 0.7$ & $3.4 \pm 0.8$ & $3.4 \pm 0.7$ & $3.6 \pm 1.3$ & $4.0 \pm 1.2$ & $3.3 \pm 0.9$ & $3.4 \pm 0.8$ & $3.5 \pm 0.7$ \\
\hline
\end{tabular}

Mean \pm SE. 


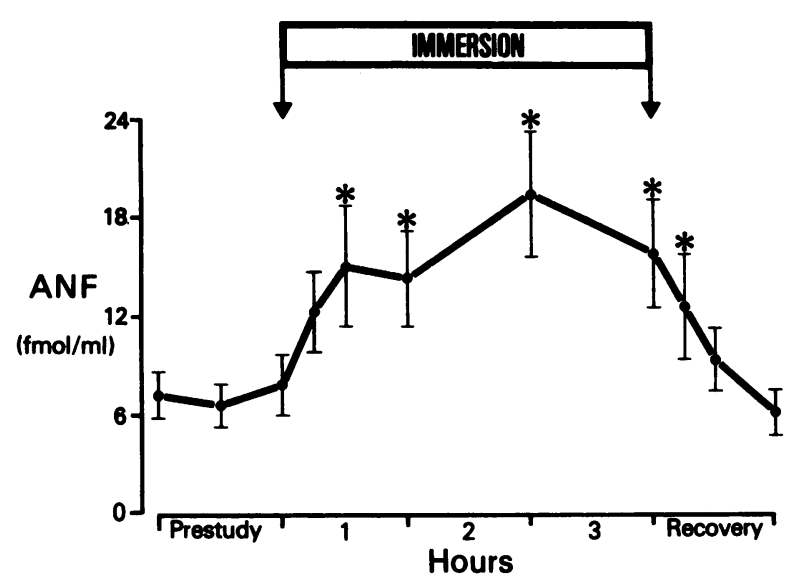

Figure 1. Effect of water immersion on plasma ANF levels in 13 normal subjects. Within $30 \mathrm{~min}$, immersion induced a marked increase in ANF that was sustained throughout immersion. Recovery was associated with a prompt return to the prestudy level. Results are mean \pm SE. ${ }^{*} P<0.05$ or more compared with the level at the end of the prestudy period.

of recovery. By 60 min of recovery, PRA was not different from the prestudy value $(P>0.05)$.

Interestingly, one subject who ingested a relatively low sodium diet manifested basal PRA levels $(14.0-17.0 \mathrm{ng} / \mathrm{ml} / \mathrm{h})$ that markedly exceeded those of the remainder of the group. Despite these markedly elevated PRA levels, immersion induced an $81 \%$ suppression of PRA to a nadir of $2.9 \mathrm{ng} / \mathrm{ml} / \mathrm{h}$.

$P A$. In general, the PA response paralleled that of PRA. As depicted in Fig. 3, immersion resulted in suppression of PA that lagged temporally behind the suppression of PRA and augmentation of ANF. The suppression of PA attained statistical significance by $120 \mathrm{~min}$ ( $P<0.005$ compared with prestudy values). By $180 \mathrm{~min}$, PA was suppressed by $57 \pm 6 \%$. Cessation of immersion was associated with a return toward prestudy values as early as $30 \mathrm{~min}$ of recovery; by $60 \mathrm{~min}$ of recovery, PA was not significantly different $(P>0.05)$ from the prestudy value.

Plasma cortisol. Plasma cortisol (Fig. 4) decreased during the $60 \mathrm{~min}$ of the prestudy period from $14 \pm 1.2$ to $10.1 \pm 1.1 \mu \mathrm{g} /$ $100 \mathrm{ml}(P<0.001$ compared with initial value). Plasma cortisol

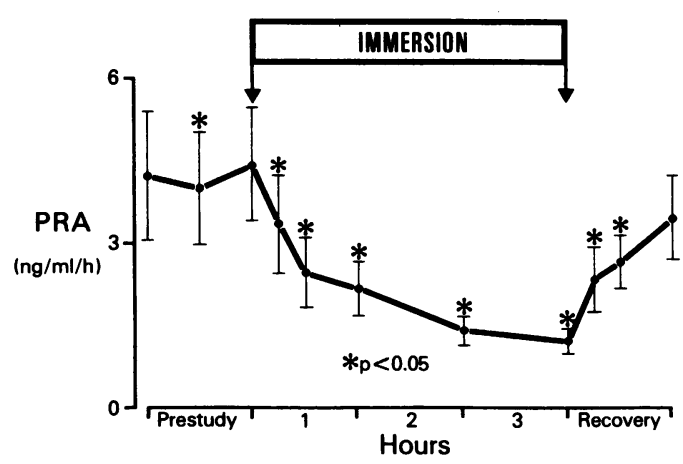

Figure 2. Effect of water immersion on PRA in 13 normal subjects. Within $15 \mathrm{~min}$, immersion induced a marked suppression of PRA that was sustained throughout immersion. Recovery was associated with a return to the prestudy level. Results are mean \pm SE. ${ }^{*} P<0.05$ or more compared with the level at the end of the prestudy period.

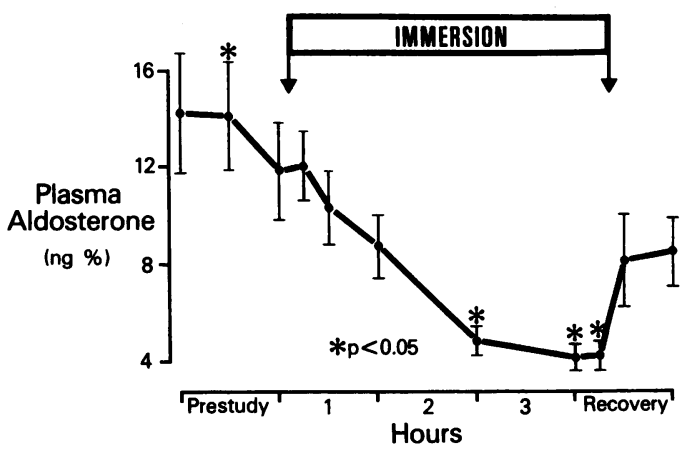

Figure 3. Effect of water immersion on PA in 13 normal subjects. Immersion induced a marked suppression of PA that achieved statistical significance after $2 \mathrm{~h}$ of immersion. Recovery was associated with a return to the prestudy level within $30 \mathrm{~min}$ following discontinuation of immersion. Results are mean \pm SE. ${ }^{*} P<0.05$ or more compared with the level at the end of the prestudy period.

declined further $(P<0.025)$ during the initial portion of the immersion period (i.e., at 15,30 , and $60 \mathrm{~min}$ ). Plasma cortisol remained stable thereafter, but recovery was associated with an increase to levels that equalled or exceeded those immediately before immersion.

Renal functional changes. The effects of $3 \mathrm{~h}$ of water immersion on urinary sodium and potassium excretion $\left(\mathrm{U}_{\mathrm{Na}} \mathrm{V}\right.$ and $\mathrm{U}_{\mathrm{K}} \mathrm{V}$ ) and other renal functional parameters are shown in Table II and Figs. 5 and 6. Renal excretory data are presented for only 12 of the 13 subjects, the remaining subject being omitted due to a urine collection error. Immersion resulted in a highly significant increase in $\mathrm{U}_{\mathrm{Na}} \mathrm{V}$, beginning with the initial hour of immersion, during which $\mathrm{U}_{\mathrm{Na}} \mathrm{V}$ increased by $>50 \%$ in 7 of 12 subjects. During the final hour of immersion, $\mathrm{U}_{\mathrm{Na}} \mathrm{V}$ was on average twofold greater than that observed during the prestudy period $(P<0.001)$. Recovery was associated with a prompt offset of the natriuresis.

Examination of the individual sodium excretory responses of the 12 subjects disclosed considerable variability. Basal sodium excretion $\left(\mathrm{U}_{\mathrm{Na}} \mathrm{V}\right)$ during the preimmersion hour varied from a low of $19 \mu \mathrm{eq} / \mathrm{min}$ (subject 1, Fig. 5) to a high of $166 \mu \mathrm{eq} / \mathrm{min}$ (subject 3 ), possibly reflecting differences in dietary $\mathrm{Na}$ intake among these individuals. Immersion failed to induce natriuresis

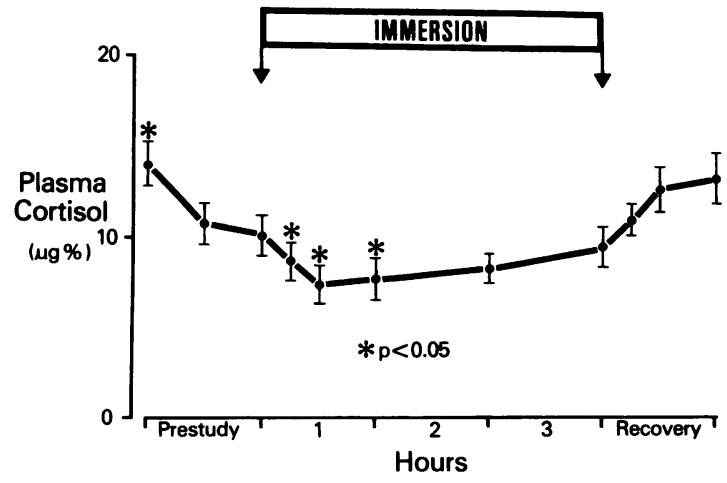

Figure 4. Effect of water immersion on plasma cortisol in 13 normal subjects. Plasma cortisol values at 15,30 , and 60 min of immersion declined as compared with the level at the initiation of immersion. Results are mean \pm SE. ${ }^{*} P<0.05$ or more compared with the level at the end of the prestudy period. 


\begin{tabular}{|c|c|c|c|c|c|}
\hline & \multirow[b]{2}{*}{ Prestudy } & \multicolumn{3}{|l|}{ Hours } & \multirow[b]{2}{*}{ Recovery } \\
\hline & & 1 & 2 & 3 & \\
\hline $\mathrm{V}(\mathrm{ml} / \mathrm{min})$ & $2.0 \pm 0.6$ & $3.9 \pm 0.6^{*}$ & $7.0 \pm 0.9^{*}$ & $5.4 \pm 0.7^{*}$ & $1.3 \pm 0.2$ \\
\hline $\mathrm{U}_{\mathrm{Na}} \mathrm{V}(\mu e q / \mathrm{min})$ & $92 \pm 12$ & $128 \pm 15^{\ddagger}$ & $160 \pm 15^{*}$ & $191 \pm 15^{*}$ & $95 \pm 15$ \\
\hline $\mathrm{U}_{\mathrm{K}} \mathrm{V}(\mu e q / \min )$ & $67 \pm 10$ & $83 \pm 11^{\ddagger}$ & $87 \pm 12$ & $76 \pm 8$ & $42 \pm 4^{\ddagger}$ \\
\hline $\mathrm{C}_{\mathrm{Cr}}(\mathrm{ml} / \mathrm{min})$ & $131 \pm 6$ & $138 \pm 11$ & $124 \pm 10$ & $130 \pm 8$ & $115 \pm 7^{\ddagger}$ \\
\hline $\mathrm{C}_{\mathrm{Na}} / \mathrm{C}_{\mathrm{Cr}} \times 100$ & $0.5 \pm 0.1$ & $0.7 \pm 0.1^{*}$ & $1.0 \pm 0.1^{*}$ & $1.1 \pm 0.1^{*}$ & $0.6 \pm 0.1$ \\
\hline $\mathrm{C}_{\mathrm{H}_{2} \mathrm{O}}(\mathrm{ml} / \mathrm{min})$ & $-0.2 \pm 0.5$ & $1.2 \pm 0.6^{*}$ & $4.2 \pm 0.8^{*}$ & $2.5 \pm 0.7^{\ddagger}$ & $-0.4 \pm 0.2$ \\
\hline $\mathrm{U}_{\mathrm{Osm}}\left(\mathrm{mOsm} / \mathrm{kg} \mathrm{H} \mathrm{H}_{2} \mathrm{O}\right)$ & $639 \pm 118$ & $293 \pm 72^{*}$ & $144 \pm 21^{*}$ & $172 \pm 17^{*}$ & $427 \pm 50$ \\
\hline
\end{tabular}

Results are mean \pm SE of 12 subjects. ${ }^{*} P<0.005$ compared with prestudy. ${ }^{\ddagger} P<0.05$ compared with prestudy.

in two subjects. Among the remaining subjects, the increment in $\mathrm{U}_{\mathrm{Na}} \mathrm{V}$ ranged from $70 \%$ above baseline to nearly $500 \%$. Of interest, subject 3 was one of the three who exhibited only slight augmentation of ANF during immersion.

Fractional excretion of sodium $\left(\mathrm{C}_{\mathrm{Na}} / \mathrm{C}_{\mathrm{Cr}} \times 100\right)$ in the 12 patients increased from $0.5 \pm 0.1 \%$ in the prestudy period to $1.1 \pm 0.1 \%$ during hour 3 of immersion $(P<0.001)$ (Table II).

In contrast to the marked natriuresis, the alterations in potassium excretion were relatively modest. As shown in Table II, the rate of potassium excretion $\left(U_{K} V\right)$ increased on average by $<30 \%$, attaining statistical significance only during hour 1 of immersion.

Creatinine clearance $\left(\mathrm{C}_{\mathrm{Cr}}\right)$ tended to increase modestly during the first hour of immersion, although this did not attain statistical significance. Nonetheless, $\mathrm{C}_{\mathrm{Cr}}$ decreased significantly $(P<0.05$ compared with prestudy) during the recovery period.

The effects of immersion on urinary flow rate $(V)$ are summarized in Table II and Fig. 6. Immersion resulted in a marked diuresis, with $\mathrm{V}$ increasing within the initial hour of immersion. By hour 2, $\mathrm{V}$ had peaked and was more than three-fold greater $(P<0.001)$ than during the preimmersion hour, although the magnitude of the response varied considerably (range, 1.5-20fold). Recovery was associated with a prompt offset, with a decrease in $\mathrm{V}$ to baseline levels $(P<0.001$ compared with hour 3).

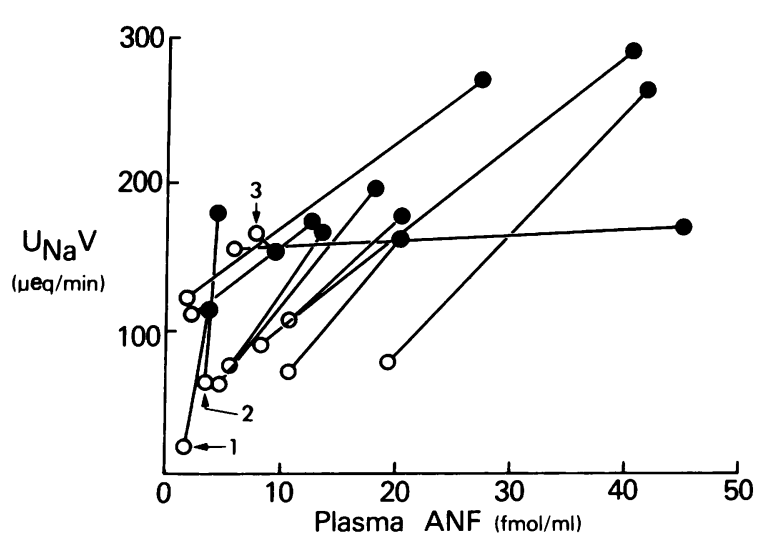

Figure 5. Immersion-induced changes in renal $\mathrm{U}_{\mathrm{Na}} \mathrm{V}$ and circulating ANF levels. Basal $\mathrm{U}_{\mathrm{Na}} \mathrm{V}$ and plasma ANF during the prestudy period are depicted as open circles and peak values attained during immersion are represented by solid circles. There was a direct correlation between peak $\mathrm{U}_{\mathrm{Na}} \mathrm{V}$ and peak plasma $\mathrm{ANF}(\mathrm{r}=0.67 ; P<0.025)$.
Free water clearance $\left(\mathrm{C}_{\mathrm{H}_{2} \mathrm{O}}\right)$ paralleled the response of $\mathrm{V}$. $\mathrm{C}_{\mathrm{H}_{2} \mathrm{O}}$ increased from $-0.2 \pm 0.5$ to $1.2 \pm 0.6 \mathrm{ml} / \mathrm{min}$ during the initial hour of immersion. Peak $\mathrm{C}_{\mathrm{H}_{2} \mathrm{O}}$ was attained on average during hour 2 ( $P<0.001$ compared with prestudy). Recovery was associated with a prompt decrease from $2.5 \pm 0.7$ to $-0.4 \pm 0.2$ $\mathrm{ml} / \mathrm{min}(P>0.5$ compared with prestudy).

Mean total urinary solute concentration $\left(U_{o s m}\right)$ varied inversely with the changes in $\mathrm{V}$. Within the initial hour of immersion, $U_{o s m}$ had decreased to $46 \%$ of that of the prestudy hour. The nadir for $U_{\text {osm }}$ was attained during hour 2 of immersion $\left(144 \pm 21 \mathrm{mOsm} / \mathrm{kg} \mathrm{H}_{2} \mathrm{O}\right)$.

Relationship of plasma ANF to renal and hormonal responses to immersion. The relationships between the induced changes in ANF and the renal responses to immersion are illustrated in Figs. 5 and 6. During acute central hypervolemia induced by water immersion, there was a direct correlation between sodium excretion (peak $\mathrm{U}_{\mathrm{Na}} \mathrm{V}$ ) and peak plasma levels of irANF ( $\mathrm{r}$ $=0.67 ; P<0.025)$. These data are depicted in Fig. 5 , in which the basal (prestudy) and peak (immersion) $U_{\mathrm{Na}} V$ levels are plotted in comparison to the basal (i.e., mean of three prestudy values) and peak plasma irANF levels. It is apparent that, with one exception, individuals exhibiting higher peak levels of plasma irANF during immersion tended to manifest higher rates of sodium excretion. In addition, there was also a relationship between peak ANF and the level of cumulative sodium excretion during

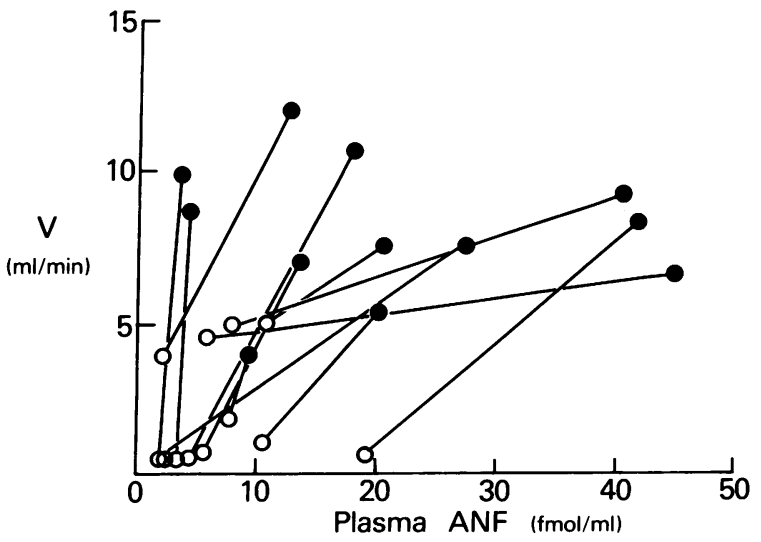

Figure 6. Immersion-induced changes in $\mathrm{V}$ and circulating ANF levels. Basal $\mathrm{V}$ and plasma ANF during the prestudy period are depicted as open circles and peak values attained during immersion are represented by solid circles. $\mathrm{V}$ varied independently of ANF during immersion $(\mathrm{r}=-0.10 ; P>0.5)$. 
the 3-h immersion period. The cumulative net natriuresis (mean $=28.7 \pm 2.4 \mathrm{meq} / 3 \mathrm{~h}$ ) varied directly with peak ANF among the 12 subjects $(r=0.60 ; P<0.05)$. Since the time course for the changes in plasma irANF and sodium excretion differed (peak irANF tended to precede peak $U_{\mathrm{Na}} \mathrm{V}$ ), we also examined the relationship between peak irANF and $\mathrm{U}_{\mathrm{Na}} \mathrm{V}$ during the corresponding urine collection and found that $\mathrm{U}_{\mathrm{Na}} \mathrm{V}$ correlated directly with peak irANF $(\mathrm{r}=+0.58 ; P<0.05)$.

In contrast to the correlation between the natriuresis and plasma ANF, renal water handling varied independently of plasma ANF. These data are depicted in Fig. 6, in which the basal (prestudy) and peak (immersion) values are plotted in comparison to the basal and peak plasma irANF levels. An examination of the relationship between plasma ANF and renal water handling disclosed that peak $\mathrm{V}$ varied independently of peak ANF ( $\mathrm{r}=-0.10 ; P>0.5)$.

Since NI resulted in a simultaneous augmentation of ANF and suppression of PRA and aldosterone, the relationships between these hormonal changes were assessed. Peak plasma ANF varied independently of both the nadir of PRA $(\mathrm{r}=-0.41 ; P$ $>0.05)$, and that of plasma aldosterone $(\mathrm{r}=-0.28 ; P>0.20)$. Furthermore, these dissociations were highlighted by the observations that three subjects did not augment ANF (subjects 1-3, Fig. 5), but decreased PRA by $69 \pm 7 \%$ and plasma aldosterone by $62 \pm 6 \%$.

Integrated hormonal influences on the natriuresis of immersion. Because the natriuresis of immersion must perforce reflect not only an augmentation of ANF, but other hormonal alterations, including PA suppression, we assessed the simultaneous contribution of ANF augmentation and PA suppression to sodium excretion with multiple regression analysis.

Peak $\mathrm{U}_{\mathrm{Na}} \mathrm{V}$ correlated directly with peak ANF levels, during immersion $(\mathrm{r}=0.676 ; P<0.025)$. Similarly, peak $\mathrm{U}_{\mathrm{Na}} \mathrm{V}$ was found to be inversely correlated with nadir PA $(\mathrm{r}=-0.66 ; P$ $<0.05)$. Nadir PA, however, varied independently of peak ANF ( $\mathrm{r}=-0.323 ; P>0.20 ; n=12$ ), suggesting that these two hormonal determinants may have independent influences on the natriuretic response to immersion. Multiple regression analysis of peak ANF and nadir PA as independent determinants of peak $\mathrm{U}_{\mathrm{Na}} \mathrm{V}$ revealed a striking correlation between these parameters ( $\mathrm{r}=0.85 ; P<0.005)$. The regression equation relating peak $\mathrm{U}_{\mathrm{Na}} \mathrm{V}$, peak ANF, and nadir PA was: $\mathrm{U}_{\mathrm{Na}} \mathrm{V}=(2.0 \pm 0.7) \mathrm{ANF}$ $-(17 \pm 6) P A+(220 \pm 30)$.

\section{Discussion}

The possible participation of cardiac atria in the control of extracellular fluid volume has been known for many years (12, 19). It is well recognized that mammalian atria have mechanoreceptors that are sensitive to stretch or distensibility induced by volume changes $(19,20)$. Recent evidence has shown that specific atrial granules (5) that share morphological and histological properties with secretory granules found in endocrine cells (21) are the source of a potent natriuretic and diuretic factor $(1,22,23)$. Changes in atrial granularity have also been shown to occur under conditions that modify salt and water balance $(24,25)$.

The present studies demonstrate that head-out water immersion generally provokes a prompt and sustained increase in plasma irANF in normal human subjects, together with reciprocal changes in plasma renin and aldosterone. In view of the compelling evidence that the effects of water immersion are me- diated by increases in central blood volume $(12,13)$, the present findings suggest that a volume-mediated increase in atrial stretch is one mechanism subserving ANF release in humans.

This finding is consistent with preliminary reports that mechanical distension of the atria leads to transient increases in plasma irANF in dogs (11). Our results may thus explain, at least in part, the observation that plasma irANF is increased in patients with congestive heart failure $(7,9)$, who presumably have chronic increases in atrial pressure. Further work is needed to define other potential mechanisms involved in the regulation of ANF release.

There was considerable variability in both the time course and the magnitude of the ANF response to immersion among the subjects studied. An increase in irANF was apparent by 15 min of immersion in 8 of 13 subjects; a nearly maximal response was achieved within 30-60 min in two of the subjects but was delayed until 2-3 $\mathrm{h}$ of sustained immersion in the remaining subjects. ANF increased by $2-10$-fold in ten of the subjects and transiently increased by 12 -fold in one of these. The determinants of these variable responses cannot be elucidated from the present studies, but because sodium balance was not controlled it is possible that differences in baseline sodium balance may have been a contributing factor. It is clear, however, that plasma irANF remained elevated by $2-4$-fold above baseline for as long as $3 \mathrm{~h}$ of immersion in 10 of the 13 subjects studied. Thus, it is probable that increases in circulating ANF could contribute to some of the biological responses to sustained increases in atrial distension.

The current observations are consistent with the postulate that increased plasma levels of ANF contribute to the natriuresis induced by immersion. Previous studies have demonstrated that the infusion of exogenous ANF promotes a natriuresis in both experimental animals $(26,27)$ and humans $(7,28-30)$. In the present study, peak plasma ANF levels correlated directly with the magnitude of the natriuretic response induced by immersion (Fig. 5). Furthermore, of the three subjects who failed to augment ANF, one failed to manifest a natriuresis (subject 3, Fig. 5). Such observations suggest a role for ANF in mediating the natriuresis of immersion. It should be pointed out that the doses of exogenous ANF required to produce similar degrees of natriuresis lead to plasma levels of the peptide far higher than those provoked by immersion (30). This discrepancy is not, however, sufficient to dismiss the possibility that levels of ANF observed in the present study might modulate renal sodium handling. Rather, it should be considered that central blood volume expansion induces, concurrently with an increase in plasma ANF, other hemodynamic, neural, and hormonal responses that might potentiate the renal response to the peptide. These circumstances would not necessarily be mimicked by exogenous ANF. Thus, whereas infusion of natriuretic doses of ANF leads simultaneously to a decrease in central venous and pulmonary wedge pressures (30), the exact opposite occurs during immersion $(12,31)$. On the other hand, in a recent study Goetz et al. (32) found that with mechanical distention of the left atrium of dogs, the increase in plasma ANF can be dissociated from the natriuresis. Aside from the possibility of species differences, this discrepancy might be explained by the marked differences in the experimental maneuvers used, beçause immersion presumably causes distention of both atria and also expands central blood volume. Although further study is required to resolve this issue, the present results strongly suggest an important contribution by ANF. 
Our data clearly indicate, however, that an increase in plasma ANF cannot fully account for the natriuresis of immersion by itself. The observation that subjects 1 and 2 (Fig. 5) manifested a natriuresis despite only minimal changes in plasma ANF illustrates this point. Indeed, previous studies have delineated an important role for induced changes in the renin-angiotensinaldosterone system and prostaglandin biosynthesis in mediating immersion-induced natriuresis (33), and there is evidence that a suppression of efferent renal sympathetic nerve activity contributes to the natriuretic response to atrial distention (34). It is probable that ANF works in concert with these other effectors to modulate sodium excretion. Moreover, it is possible that certain mechanisms might predominate in individual subjects or under different baseline states of sodium balance.

The alterations in glomerular filtration rate (GFR) that occurred during immersion merit comment. In the present study, GFR, as assessed by creatinine clearance, tended to increase modestly, although these changes did not attain statistical significance. Increases in GFR have accompanied the administration of ANF in rats $(35)$, dogs $(26,27)$, and, perhaps to a lesser extent, man $(29,30)$. In view of the complex mechanisms of natriuresis during water immersion, the present studies do not establish the mechanisms underlying the natriuretic response to ANF per se.

Although immersion was associated with both a diuresis and a natriuresis, it is clear that these two renal excretory responses can be dissociated $(12,36,37)$. In the present study, the temporal profiles of the natriuresis and diuresis induced by immersion differed, with peak $\mathrm{V}$ preceding peak $\mathrm{U}_{\mathrm{Na}} \mathrm{V}$ (Table II). Similarly, the relationships between peak plasma ANF levels and the magnitude of the natriuretic and diuretic responses to immersion differed. Whereas peak plasma ANF correlated directly with peak $\mathrm{U}_{\mathrm{Na}} \mathrm{V}$, no such correlation was observed between peak plasma ANF and peak V (Fig. 6). These findings suggest that under the conditions of the present study ANF does not constitute a major determinant of the diuretic response to immersion.

Several recent observations bear on the issue of whether ANF is secreted in response to volume expansion in humans. Shenker et al. (9) assessed the effect of changes in sodium intake on plasma irANF levels in 10 normal human subjects. They observed that plasma ANF levels doubled when the subjects went from a lowsodium diet to a high-sodium diet. Yamaji et al. (38) demonstrated that saline administration (500 ml infused over $45 \mathrm{~min}$ ) resulted in a doubling of plasma ANF levels. More recently, Sagnella et al. (39) reported that in response to the administration of 21 of $0.9 \%$ saline, infused over $1 \mathrm{~h}$, immunoreactive ANF levels increased $\sim$ three-fold. In the present study, a similar mean three-fold increase in circulating ANF was observed in response to water immersion (Fig. 1). The demonstration that 2-1 saline administration and water immersion induced similar increments in plasma ANF levels is of interest and probably attributable to the identical central volume expansive effects of these two maneuvers. Indeed, we have previously demonstrated that the central hemodynamic and renal effects of immersion are quantitatively identical to those produced by a $10 \%$ expansion of extracellular fluid volume with isotonic saline (2 liters/120 $\min )$ (13).

The suppression of PRA and PA that occur during immersion might also be mediated in part by an increase in plasma ANF. In addition to inducing a marked natriuresis and diuresis, infusion of exogenous ANF has been shown to produce reversible decreases in PRA and PA in experimental animals (26) and humans (30). In the present study, however, we observed that PRA was suppressed in response to immersion-induced central hypervolemia in all subjects, whereas ANF did not increase substantially in 3 of the 13 subjects. This dissociation of PRA and ANF suggests that although ANF may indeed modulate renin secretion, other determinants (e.g., changes in renal-sympathetic nerve traffic) are likely to play a prominent role in regulating renin secretion following blood volume redistribution. Although the effect of aldosterone could in part result from a decrease in circulating renin, and hence angiotensin II, there is evidence that ANF can decrease aldosterone independently of changes in PRA (40), consistent with direct effect of the peptide on steroidogenesis, as has been demonstrated in vitro (41-43). It remains possible, therefore, that the immersion-induced increases in plasma ANF demonstrated herein may have contributed to the concurrent changes in both PRA and PA, although further work will be required to establish this.

The present study also suggests that immersion may have effects on the pituitary-adrenal axis. Although the tendency for plasma cortisol to fall at the onset of immersion may well have been no greater than that expected by the normal diurnal variation in ACTH secretion, the distinct rise in plasma cortisol during the recovery period (Fig. 4) cannot be explained on this basis. It is of interest that infusion of ANF in normal humans has been shown to produce a similar pattern of response, namely a tendency for cortisol to fall, followed by a marked rebound increase in cortisol after termination of the infusion (30). These observations raise the possibility that ANF might have an inhibitory effect on either cortisol or ACTH release, but further study is required to delineate the mechanism(s) involved.

The present study demonstrates clearly that a physiological manipulation that acutely augments central blood volume and induces atrial distension is associated with marked stimulation of circulating irANF. Furthermore, immersion-induced natriuresis was generally of greater magnitude in those subjects who increase their ANF levels during immersion. Collectively, these findings lend strong support to the hypothesis that an augmentation of ANF release constitutes one of the important mediators of the natriuresis of water immersion in normal humans. Although theoretical considerations suggest that plasma aldosterone suppression during immersion might constitute an integrated response to both suppression of the renin-angiotensin axis and augmentation of ANF, the current studies do not permit an assessment of this possibility. Since central hypervolemia apparently evokes neural reflexes that profoundly inhibit renin release, the simultaneous decrease of PRA confounds any assessment of the role of ANF per se in PA suppression.

Clearly, augmentation of ANF release is but one potential mechanism for the renal and hormonal responses to atrial distension. Aside from the other humoral or paracrine mediators cited above, there is compelling evidence that neural reflexes affecting vasopressin release and efferent sympathetic nerve traffic mediate the diuretic response to mechanical distention of the atria $(12,34)$, and such reflexes probably participate in the inhibition of renin release and the natriuresis as well $(12,14,15$, 34). Additional investigation will be required to determine the importance of ANF per se in mediating the renal and hormonal response to immersion-induced central hypervolemia in both normal humans and patients with edematous disorders (44). The results described in this report nonetheless make tenable 
the hypothesis that ANF is a circulating hormone that participates in the complex neuro-humoral control of the circulation, the renin-angiotensin-aldosterone system, and extracellular volume.

\section{Acknowledgments}

We are indebted to Phillip Sonke and Ana Sjoberg for their technical assistance and to Gilda Manicourt for her expert preparation of the manuscript.

These studies were supported in part by designated Veterans Administration Research funds (2456-01) and by grant HL18323-SCR.

\section{References}

1. DeBold, A. J., H. R. Borenstein, A. T. Veress, and H. A. Sonnenberg. 1981. A rapid and potent natriuretic response to intravenous injection of atrial myocardial extracts in rats. Life Sci. 28:89-94.

2. Maack, T., M. J. F. Camargo, H. D. Kleinert, J. H. Laragh, and S. A. Atlas. 1985. Atrial natriuretic factor: structure and functional properties. Kidney Int. 27:607-615.

3. Cantin, M., and J. Genest. 1985. The heart and the atrial natriuretic factor. Endocrine Reviews. 6:107-127.

4. Needleman, P., S. P. Adams, B. R. Cole, M. G. Currie, D. M. Geller, M. L. Michener, C. B. Saper, D. Schwartz, and D. G. Standaert. 1985. Atriopeptins as cardiac hormones. Hypertension (NY). 7:469-482.

5. Tanaka, I., K. S. Misona, and T. Inagami. 1984. Atrial natriuretic factor in rat hypothalamus, atria and plasma: determination by specific radioimmunoassay. Biochem. Biophys. Res. Commun. 124:663-668.

6. Lang, R. E., H. Thoelken, D. Ganten, F. C. Luft, H. Ruskoaho, and T. H. Unger. 1985. Atrial natriuretic factor is a circulating hormone, stimulated by volume loading. Nature (Lond.). 314:264-266.

7. Tikkanen, I., K. Metsarinne, F. Fyhrquist, and R. Leidfenius. 1985. Plasma atrial natriuretic peptide in cardiac disease and during infusion in healthy volunteers. Lancet. ii:66-69.

8. Larose, P., S. Meloche, P. du Souich, A. DeLean, and H. Ong. 1985. Radioimmunoassay of atrial natriuretic factor: human plasma levels. Biochem. Biophys. Res. Commun. 130:553-558.

9. Shenker, Y., R. S. Sider, E. A. Ostafin, and R. J. Grekin. 1985. Plasma levels of immunoreactive atrial natriuretic factor in healthy subjects and in patients with edema. J. Clin. Invest. 76:1684-1687.

10. Epstein, M., R. D. Loutzenhiser, E. Friedland, R. M. Aceto, M. J. F. Camargo, and S. A. Atlas. 1986. Increases in circulating atrial natriuretic factor during immersion-induced central hypervolemia in normal humans. J. Hypertens. 4(Suppl. 2):92.

11. Courneya, C. A., A. J. Rankin, J. R. Ledsome, and N. Wilson. 1985. Time course of changes in plasma atrial natriuretic peptide concentration during atrial distension. Fed. Proc. 44:1729. (Abstr.)

12. Epstein, M. 1978. Renal effects of head-out water immersion in man: implications for an understanding of volume homeostasis. Physiol. Rev. 58:529-581.

13. Levinson, R., M. Epstein, M. A. Sackner, and R. Begin. 1977. Comparison of the effects of water immersion and saline infusion on central hemodynamics in man. Clin. Sci. Mol. Med. 52:343-350.

14. Epstein, M., D. S. Pins, J. Sancho, and E. Haber. 1975. Suppression of plasma renin and plasma aldosterone during water immersion in normal man. J. Clin. Endocrinol. Metab. 41:618-625.

15. Epstein, M., R. Re, S. Preston, and E. Haber. 1979. Comparison of the suppressive effects of water immersion and saline administration on renin-aldosterone in normal man. J. Clin. Endocrinol. Metab. 49: 358-363.

16. Preibisz, J. J., J. E. Sealey, R. M. Aceto, and J. H. Laragh. 1982. Plasma renin activity measurements: an update. Cardiol. Rev. Rep. 5: 787-804.

17. Buhler, F. R., J. E. Sealey, and J. H. Laragh. 1974. Radioim- munoassay of plasma aldosterone. In Hypertension Manual. Dun-Donnelley, New York. 665-669.

18. Atlas, S. A., H. D. Kleinert, M. J. Camargo, A. Januszewicz, J. E. Sealey, J. H. Laragh, J. W. Schilling, J. A. Lewicki, L. K. Johnson, and T. Maack. 1984. Purification, sequencing and synthesis of natriuretic and vasoactive rat atrial peptides. Nature (Lond.). 309:717-720.

19. Gauer, O. H., J. P. Henry, and C. Behn. 1970. The regulation of intracellular fluid volume. Ann. Rev. Physiol. 32:547-595.

20. Goetz, K. L., G. G. Bond, and D. D. Bloxam. 1975. Atrial receptors and renal function. Physiol. Rev. 55:157-205.

21. Jamieson, J. D., and G. E. Palade. 1964. Specific granules in atrial muscle. J. Cell Biol. 23:151-172.

22. deBold, A. J., and T. A. Salerno. 1982. Natriuretic activity of extracts obtained from hearts of different species and from various rat tissues. Can. J. Physiol. Pharmacol. 61:127-130.

23. Garcia, R., M. Cantin, G. Thibault, H. Ong, and J. Genest. 1982. Relationship of specific granules to the natriuretic and diuretic activity of rat atria. Experientia (Basel). 38:1071-1073.

24. Marie, J. P., H. Guillemot, and P. Y. Hatt. 1976. Le degre de granulation des cardiocytes auriculaires. Etude planimetrique au cours de differents apports d'eau et du sodium chez le rat. Pathol. Biol. 24: 549-554.

25. deBold, A. J. 1979. Heart atrial granularity effects changes in water electrolyte balance. Proc. Soc. Biol. Med. 161:508-511.

26. Maack, T., D. N. Marion, M. J. F. Camargo, H. D. Kleinert, J. E. Laragh, E. D. Vaughan, Jr., and S. A. Atlas. 1984. Effects of auriculin (atrial natriuretic factor) on blood pressure, renal function, and the reninaldosterone system in dogs. Am. J. Med. 77:1069-1075.

27. Burnett, Jr., J. C., J. P. Granger, and T. S. Opgenorth. 1984. Effects of synthetic atrial natriuretic factor on renal function and renin release. Am. J. Physiol. 247:F863-F866.

28. Richards, A. M., H. Ikram, T. G. Yandle, M. G. Nicholls, M. W. I. Webster, and E. A. Espiner. 1985. Renal, haemodynamic, and hormonal effects of human alpha atrial natriuretic peptide in healthy volunteers. Lancet. i:545-548.

29. Weidman, P. N., L. Hasler, M. P. Gnadinger, R. E. Lang, D. E. Uehlinger, S. Shaw, W. Rascher, and F. C. Reubi. 1986. Blood levels and renal effects of atrial natriuretic peptide in normal man. J. Clin. Invest. 77:734-742.

30. Cody, R. J., S. A. Atlas, J. H. Laragh, S. H. Kubo, A. B. Covit, K. S. Ryman, A. Shaknovich, K. Pondolfino, M. Clark, M. J. F. Camargo, R. M. Scarborough, and J. A. Lewicki. 1986. Atrial natriuretic factor in normal subjects and heart failure patients. Plasma levels and renal, hormonal, and hemodynamic responses to peptide infusion. J. Clin. Invest. 78:1362-1374.

31. Norsk, P., F. Bonde-Petersen, and J. Warberg. 1985. Central venous pressure and plasma arginine vasopressin during water immersion in man. Eur. J. Appl. Physiol. Occup. Physiol. 54:71-78.

32. Goetz, K. L., B. C. Wang, P. G. Geer, R. J. Leadley, Jr., and H. W. Reinhardt. 1986. Atrial stretch increases sodium excretion independently of release of atrial peptides. Am. J. Physiol. 250:R946-R950.

33. Epstein, M., M. Lifschitz, D. S. Hoffman, and J. H. Stein. 1979. Relationship between renal prostaglandin $\mathrm{E}$ and renal sodium handling during water immersion in normal man. Circ. Res. 45:71-80.

34. DiBona, G. F. 1984. Renal neural activity in hepatorenal syndrome. Kidney Int. 25:841-853.

35. Huang, C. L., J. Lewicki, L. K. Johnson, and M. G. Cogan. 1985. Renal mechanism of action of rat atrial natriuretic factor. J. Clin. Invest. 75:769-773.

36. Epstein, M., A. G. DeNunzio, and R. D. Loutzenhiser. 1981. Effects of vasopressin administration on diuresis of water immersion in normal humans. J. Appl. Physiol. 51:1384-1387.

37. Lifschitz, M. D., M. Epstein, and O. Larios. 1985. Relationship between urine flow rate and prostaglandin $\mathrm{E}$ excretion in human beings. J. Lab. Clin. Med. 105:234-238.

38. Yamaji, T., M. Ishibashi, and F. Takaku. 1985. Atrial natriuretic factor in human blood. J. Clin. Invest. 76:1705-1709. 
39. Sagnella, G. A., N. D. Markandu, A. C. Shore, and G. A. MacGregor. 1985. Effects of changes in dietary sodium intake and saline infusion on immunoreactive atrial natriuretic peptide in human plasma. Lancet. i:1208-1210.

40. Volpe, M., G. Odell, H. D. Kleinert, M. J. F. Camargo, J. H. Laragh, J. A. Lewicki, T. Maack, E. D. Vaughan, Jr., and S. A. Atlas. 1984. Antihypertensive and aldosterone lowering effects of synthetic atrial natriuretic factor in renin dependent renovascular hypertension. J. Hypertens. 2(Suppl. 3):313-315.

41. Ataraski, K., P. P. Mulrow, R. Franco-Saez, R. Snajdar, and J. Rapp. 1984. Inhibition of aldosterone production by an atrial extract. Science (Wash. DC). 224:992-994.
42. Goodfriend, T. L., M. Elliot, and S. A. Atlas. 1984. Actions of synthetic atrial natriuretic factor on bovine adrenal glomerulosa. Life Sci. 35:1675-1682.

43. De Lean, A., K. Racz, J. Gutkowska, T. T. Nguyen, M. Cantin, and J. Genest. 1984. Specific receptor-mediated inhibition by synthetic atrial natriuretic factor of hormone-stimulated steroidogenesis in cultured bovine adrenal cells. Endocrinology. 115:1636-1638.

44. Epstein, M., R. Preston, R. Aceto, M. J. F. Camargo, R. Loutzenhiser, and S. Atlas. 1987. Dissociation of plasma irANF and renal sodium handling in cirrhotic humans undergoing water immersion. Kidney Int., 31:269. 